\title{
Material de educação ambiental como estratégia de prevenção da leptospirose para uma comunidade urbana reassentada
}

\author{
Environmental education booklet as a prevention strategy \\ for leptospirosis in a relocated urban community
}

\author{
Marilise Oliveira Mesquita, Graziella Chaves Trevilato ${ }^{1}$, Luiza de Holleben Saraiva', \\ Michelle da Silva Schons ${ }^{1}$, Maria Isabel Ferreira Garcia ${ }^{1}$
}

\begin{abstract}
Resumo
A leptospirose é uma doença comum em locais urbanizados sem saneamento básico. A bactéria causadora é transmitida pelos roedores e pode contaminar os cães e estes, as pessoas, sendo a enfermidade considerada zoonótica. O objetivo deste estudo foi conhecer os riscos ambientais à saúde dos moradores de um novo reassentamento urbano, identificando problemas e construindo possíveis soluções, concretizadas em um material de educação ambiental com as demandas específicas encontradas nessa comunidade. Foram realizadas entrevistas domiciliares com perguntas sobre os hábitos e costumes das pessoas com relação aos cuidados com os animais de estimação, presença de animais sinantrópicos nos domicílios e manejo dos resíduos sólidos domésticos. Também foram efetuadas 142 coletas de amostras de sangue nos cães destes domicílios, para sorologia anti-leptospira, das quais 26 (18,3\%) foram soropositivas; as sorovariedades mais frequentes foram Icterohaemoragiae (46\%) e Canicola (26,9\%). A partir dos dados obtidos nas entrevistas domiciliares e dos resultados das análises sanguíneas dos cães, foi possível perceber os principais problemas ambientais e os riscos à saúde a que essa comunidade estava exposta. Foi então elaborado um material educativo para dar respostas e orientações aos problemas ambientais específicos observados e apontados pela comunidade.

Palavras-chave: saneamento urbano; leptospirose; educação ambiental.
\end{abstract}

\begin{abstract}
Leptospirosis is a common disease in urbanized locations without basic sanitation. The bacteria is transmitted by rodents and can infect dogs that in turn can transmit the disease to people, with the disease being classified as zoonotic. This study aimed to discover what were the environmental health risks for residents of a new urban resettlement, identifying problems and building possible solutions that were implemented into an environmental education material meeting the specific demands encountered in this community. Home interviews were performed, with questions about habits and behavior of the community related to petcare, presence of synanthropic animals in the household and management of solid waste. The group collected 142 blood samples of dogs belonging to these households, for anti-Leptospiral serology. The results were $26(18.3 \%)$ positive, and the most frequent serovars were Icterohaemoragiae (46\%) and Canicola (26.9\%). From the data obtained from household interviews and blood tests results from dogs, it was possible to observe the main environmental problems and health risks that this community was subject to. It was then developed an educational material to provide answers and guidance to specific environmental problems observed and raised by the community.
\end{abstract}

Keywords: urban sanitation; leptospirosis; environmental education.

'Universidade Federal do Rio Grande do Sul (UFRGS) - Porto Alegre (RS), Brasil.

Trabalho realizado na Universidade Federal do Rio Grande do Sul (UFRGS) - Porto Alegre (RS), Brasil.

Endereço para correspondência: Marilise Oliveira Mesquita - Rua São Manoel, 963 - Campus da Saúde - CEP: 90620-110 - Porto Alegre (RS), Brasil -

Email: marilise.mesquita@ufrgs.br

Fonte de financiamento: Pro-Reitoria de Pesquisa da Universidade Federal do Rio Grande do Sul (PROPESQ/UFRGS).

Conflito de interesses: nada a declarar.

Cad. Saúde Colet., 2016, Rio de Janeiro, 24 (1): 77-83 


\section{INTRODUÇÃO}

A contaminação ambiental produzida por assentamentos urbanos irregulares e sem saneamento básico tem importante impacto na saúde dos moradores desses locais. A leptospirose está entre as doenças bastante conhecidas pelas pessoas que vivem nesses contextos urbanos ${ }^{1}$. Comunidades de catadores tendem a acumular resíduos sólidos em torno das residências, o que atrai animais sinantrópicos, como os ratos, e, com eles, doenças para a comunidade, como a leptospirose, comum em áreas sem saneamento. A leptospirose é uma doença infecto-contagiosa aguda que acomete animais e pessoas causada por uma bactéria do gênero Leptospira, que tem sido amplamente divulgada como causa de adoecimento em comunidades sem infraestrutura, produzindo incapacidade temporária, internação hospitalar e maior incidência de morte em crianças e idosos ${ }^{2}$. O rato é portador da Leptospira spp., porém animais domésticos, assim como o homem, são portadores acidentais, que podem adoecer ao contrair a enfermidade. Os cães podem ser reservatório e fonte da bactéria, sendo um potencial transmissor da doença para humanos ${ }^{3}$.

A Vila Dique de Porto Alegre é uma comunidade que se instalou em uma área de ocupação irregular, no início da década de 1960, às margens de um arroio ${ }^{4}$, e que passou a conviver com lixo e esgoto doméstico a céu aberto ${ }^{5}$. Essas pessoas estavam sob constante ameaça de contrair leptospirose devido à intensa presença de ratos e animais domésticos como cães, suínos e equinos, além da falta de saneamento. Casos de estresse, hemorragia interna, nervos, gripe, crise renal, doença do rato e bronquite estão entre os agravos à saúde mais citados pelos catadores da Vila Dique de Porto Alegre ${ }^{6}$. A comunidade da Vila Dique foi transferida, gradativamente, desde 2009, para um novo reassentamento urbano, construído para albergar essas famílias. Até o início de 2013, cerca de mil famílias já haviam sido removidas. No entanto, mesmo em novo local com infraestrutura urbana e saneamento básico, a comunidade permaneceu com hábitos e costumes do antigo local de moradia, que propiciavam riscos à leptospirose.

O objetivo deste estudo foi conhecer os riscos ambientais à saúde dos moradores do reassentamento urbano oriundos da Vila Dique de Porto Alegre, identificando problemas e construindo possíveis soluções, ilustradas em um material de educação ambiental com as demandas específicas encontradas nessa comunidade.

\section{METODOLOGIA}

O trabalho foi realizado em uma comunidade urbana reassentada em área com infraestrutura, saneamento básico e equipamentos urbanos, cujos moradores eram provenientes de área irregular e sem saneamento básico no município de Porto Alegre, Rio Grande do Sul, Brasil. Foram realizadas 89 entrevistas domiciliares para aplicação de um questionário com perguntas estruturadas e semiestruturadas, sobre os hábitos e costumes da comunidade com relação ao ambiente, cuidados com os animais de estimação, presença de animais sinantrópicos e manejo dos resíduos sólidos domésticos. As visitas nos domicílios foram realizadas semanalmente e tiveram início em novembro de 2011, finalizando em dezembro de 2012. A participação dos moradores da comunidade deu-se de forma voluntária e sigilosa, através do uso do Termo de Consentimento Livre e Esclarecido. Os critérios de inclusão para a entrevista foram o domicílio apresentar pelo menos um cão e o entrevistado ter acima de 16 anos. Também foram efetuadas 142 coletas de amostras de sangue nos cães dos domicílios, para identificação da soropositividade à Leptospira spp. canina na comunidade. Os animais dos quais foram coletadas não haviam sido vacinados para leptospirose anteriormente, segundo informação dos proprietários.

As amostras foram enviadas para o Laboratório de Leptospirose do Instituto Desiderio Finamor (IPVDF-FEPAGRO Saúde Animal), localizado em Eldorado do Sul, Região Metropolitana de Porto Alegre, RS, Brasil, e testadas para sorologia antileptospira. A técnica utilizada pelo laboratório de Leptospirose do IPVDF é a Soroaglutinação Microscópica (SAM), sendo utilizados no diagnóstico 18 sorovariedades de leptospira: L. australis (Ballico), L. autumnalis (Akiyami A), L. ballum (Mus 127), L. canicola (Hondutrecht), L. copenhageni (M 20), L. celledoni (Celledoni), L. cynopteri (3522 C), L. hardjo (Hardjo prajitno), L. icteroahemorrhagiae (RGA), L. javanica (Veldratbataviae 46), L. panama (CZ 214), L. pyrogenes (Salinem), L. pomona (Pomona), L. tarassovi (Perepelitsin), L. wolffi (3705), L. castelonis (Castellon 3), L. bataviae (Van tienen) e L. saxkoebing (Mus 24). Essa técnica permite determinar de forma quantitativa o título dos anticorpos para cada uma das sorovariedades presentes da bactéria, considerando positivos os animais que apresentem títulos iguais ou superiores à 1:100, conforme proposto pela Organização Internacional para Saúde Animal (OIE), Organização Pan-americana de Saúde (OPS) e a Organização Mundial da Saúde (OMS). Foram avaliadas as frequências de animais soropositivos e as frequências das sorovariedades encontradas.

A última etapa do trabalho foi a elaboração de um material de educação ambiental a partir dos problemas e dúvidas levantados pelos moradores nas entrevistas domiciliares. A etapa de elaboração do material educativo ocorreu em 2013 e em 2014, e as ilustrações desse material foram feitas com fotos de moradores, devidamente autorizadas, mediante termo de autorização de uso de imagem para fins didático-pedagógicos e acadêmicos, e também através de desenhos elaborados para esse material.

O material foi distribuído para todos os alunos da Escola de Ensino Fundamental Porto Novo, construída para atender as 
crianças dessa comunidade e localizada dentro do reassentamento urbano, no período letivo de 2015. A idade dos escolares era de 5 a 12 anos e a escola tinha cerca de 250 alunos matriculados. Antes da distribuição em cada turma, o projeto foi apresentado para as crianças e professores, com o auxílio de um projetor. Foram mostradas fotos das atividades do projeto e explicados os seus objetivos e resultados.

O projeto foi submetido e aprovado pelo comitê de ética em pesquisa da instituição envolvida sob o número 20648.

\section{RESULTADOS E DISCUSSÃO}

Das 142 amostras de sangue canino analisadas, 18,3\% (26 cães) foram soropositivas para leptospirose. As sorovariedades mais frequentes foram Icterohaemorrhagiae (46\%) e Canicola (27\%). Esses resultados assemelham-se aos de vários estudos epidemiológicos realizados nas mais diversas regiões do país ${ }^{7-9}$. Entretanto, a alta prevalência observada da sorovariedade Icterohaemorrhagiae indica risco para a saúde da população, visto ser esta a sorovariedade que produz o quadro clínico mais severo para o ser humano ${ }^{10}$. Observa-se em diversos trabalhos que a soropositividade à Leptospira spp. no meio urbano está em torno de $15 \%$ a $30 \%$ e que no meio rural ela se torna menos prevalente $^{11}$. Essa maior prevalência da leptospirose canina no meio urbano se deve, principalmente, ao fácil acesso dos roedores a abrigo, alimento e água, os três requisitos básicos para sua grande proliferação ${ }^{12}$.

Através da análise das entrevistas realizadas foi possível conhecer a percepção ambiental da comunidade reassentada, bem como os riscos de contaminação por leptospirose. As questões referentes à promoção da saúde se tornaram temas para serem incluídos no material de educação ambiental, que foi elaborado para ser atrativo e de fácil compreensão. A proposta da elaboração desse material foi feita com base nas lacunas de conhecimentos e dúvidas demonstradas pelos moradores, portanto, ele se legitimou como um instrumento educativo dentro das estratégias de prevenção da leptospirose e da promoção em saúde. A elaboração do material teve ainda o propósito de incluir imagens das pessoas da comunidade durante o trabalho realizado, assim cada entrevistado pôde se identificar como parte dele. Nesse sentido, a linguagem foi acessível para público com baixa escolaridade, pois essa foi uma característica observada nas entrevistas. Das pessoas entrevistadas, $57 \%$ apresentavam apenas o ensino fundamental incompleto. De 89 entrevistados, uma pessoa apresentava o ensino superior incompleto e nenhum entrevistado possuía graduação. Lermen e Fisher ${ }^{13}$ descrevem que um maior grau de escolaridade gera um maior senso crítico sobre os fatores que podem agredir o ambiente e, em $89 \%$ dos casos, a principal fonte de conhecimento sobre o meio ambiente é a escola. Porém, Dias $^{14}$ destaca que a educação ambiental deve chegar a todas as pessoas, onde quer que elas estejam, dentro ou fora das escolas, nas associações comunitárias, religiosas, culturais, esportivas, profissionais, ou seja, ela deve ir onde as pessoas estão.

Para o material foram selecionados temas que implicavam na prevenção de doenças e promoção da saúde da comunidade. Lermen e Fisher ${ }^{13}$, em outra comunidade, no mesmo município, também observaram que os entrevistados que trabalhavam com materiais recicláveis só conseguiam associar sua atividade com riscos à saúde quando citavam os ratos e a mistura de lixo seco com o orgânico. Com essa afirmação, percebe-se que as pessoas que trabalham com materiais recicláveis reconhecem os ratos como ameaça à sua saúde.

Com relação aos animais sinantrópicos, as respostas dos questionários indicaram que $100 \%$ dos domicílios, no novo reassentamento, apresentavam pelo menos um desses animais: ratos, carrapatos, pulgas e pombos, e em $61 \%$ das casas, mais de um tipo (Figura 1). O convívio com animais sinantrópicos parecia fazer parte da rotina dessa comunidade reassentada, pois, no presente estudo, $27 \%$ das residências que apresentavam animais sinantrópicos não utilizavam nenhuma estratégia de controle. Quadro semelhante foi encontrado por Santos et al. ${ }^{15}$ : 90\% dos domicílios de catadores localizados na periferia de Brasília tinham ratos e baratas.

Conforme pesquisa desenvolvida por Jorge et al. ${ }^{16}$, a presença de roedores nos domicílios e o hábito de manter os cães soltos aumentam o risco de esses animais se contaminarem com a bactéria e tornarem-se potenciais disseminadores da doença. Os autores concluíram ser importante o esclarecimento da população local quanto à epidemiologia da leptospirose e importância da prevenção, através de medidas sanitárias aplicadas ao ambiente e aos animais de estimação.

A antiga Vila Dique era popularmente conhecida como local de muitos casos de leptospirose humana ${ }^{1}$. Durante as entrevistas do presente estudo, as pessoas foram questionadas sobre se conheciam alguém que tivesse sido acometido por leptospirose e $40 \%$ responderam que sim, e eram relatos de conhecidos ou parentes moradores da antiga Vila Dique. Entretanto, apenas 29\% das pessoas entrevistadas responderam que sabiam que o cão pode transmitir leptospirose (Figura 2). Como afirma Genovez ${ }^{3}$, animais que vivem em áreas urbanas, cujas condições sanitárias e de infraestrutura são precárias, junto a lixões, esgotos a céu aberto, depósitos de materiais descartados, restos alimentares e promiscuidade com outras espécies animais, [...] constituem particularmente [...] população de risco.

Quanto à segregação dos resíduos sólidos em recicláveis e não recicláveis, $60 \%$ dos entrevistados disseram que faziam a separação do lixo. O motivo principal para a segregação, em $68 \%$ das respostas, foi geração de renda. A comunidade tinha forte relação com essa atividade, pois muitas famílias que viviam na Vila Dique trabalhavam com carroças e carrinhos, 


\section{Animais indesejados}
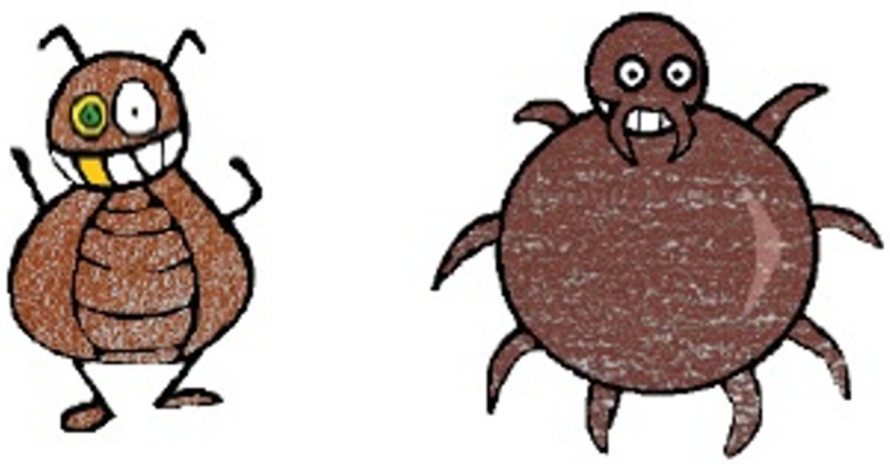

Perguntamos às pessoas da comunidade quais animais indesejados havia em suas casas.

\section{Respostas dos entrevistados quanto d presença de animais indesejados dentro de casa ou no pátio:} $63 \%$

Gráfico 6:
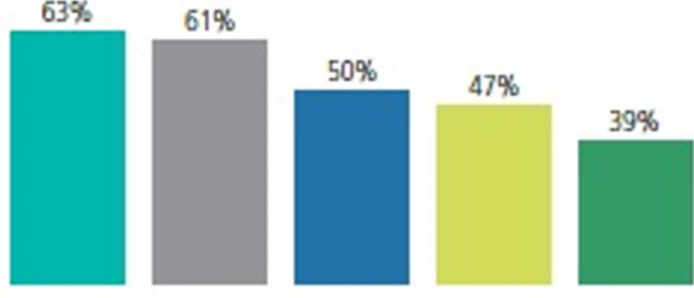

Representaçāo gráfica das respostas obtidas nas 89 entrevistas realizadas nos anos de 2012 e 2013 no Reassentamento Urbano Porto Novo, zona norte de Porto Alegre/RS.

CARRAPATOS

RATOS

POMBOS

MOSQUITOS

PULGAS

Figura 1. Página do material de educação ambiental para o Conjunto Habitacional Porto Novo que ilustra a frequência de domicílios com animais sinantrópicos, 2015. Fonte: Mesquita et al. ${ }^{17}$

coletando materiais recicláveis pela cidade ${ }^{6}$. Muitas das mulheres entrevistadas dispunham de amplo conhecimento técnico sobre quais resíduos são passíveis de reciclagem e quais são os mais rentáveis. Essas mulheres trabalhavam como catadoras, ou em galpão de reciclagem, no entanto, se observou que quando essas pessoas deixavam de trabalhar com separação de material reciclável acabavam não segregando mais, nem em seu próprio domicílio. Nesse sentido, a percepção da reciclagem apresentou-se restrita à geração de renda, sem consciência mais ampla sobre os impactos ambientais. Da mesma forma,
Lermen e Fisher ${ }^{13}$ observaram que a visão que os moradores da Vila Parque Santa Anita, localizada também no município de Porto Alegre, tiveram do meio ambiente parece diretamente relacionada ao seu trabalho, pois apesar de tirarem do lixo o seu sustento, e terem com ele contato frequente, menos da metade dos catadores considera o lixo como parte do seu meio ambiente.

Ao final de cada entrevista, abria-se um espaço para um maior aprofundamento das questões abordadas, no qual se estabelecia uma troca de conhecimentos, contemplando explicações sobre zoonoses (leptospirose em especial) e a 


\section{Você sabia que o cão pode transmitir leptospirose?}

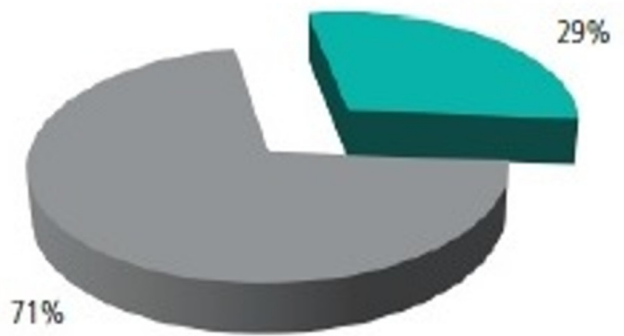

\section{Gráfico 1:}

Representaçāo gráfica das respostas obtidas nas 89 entrevistas realizadas nos anos de 2012 e 2013 no Reassentamento Urbano

SIM Porto Novo, zona norte de Porto Alegre/RS.

\section{Você conhece alguém} que ja teve leptospirose?

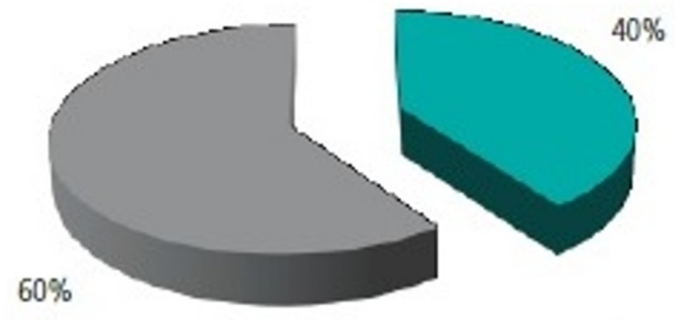

Gráfico 2:

Representaçāo gráfica das respostas obtidas nas 89 entrevistas realizadas nos anos de 2012 e 2013 no Reassentamento Urbano

SIM Porto Novo, zona norte de NÄO — Porto Alegre/RS.

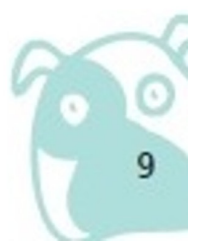

Figura 2. Página do material de educação ambiental para o Conjunto Habitacional Porto Novo, com gráficos que ilustram a percepção ambiental dos moradores entrevistados sobre a leptospirose, 2015. Fonte: Mesquita et al. ${ }^{17}$

importância das condições sanitárias ambientais para a saúde da comunidade, ressaltando que se deve buscar atendimento médico caso o indivíduo apresente sinais e sintomas da leptospirose. A partir de todos os dados obtidos, o material foi elaborado visando dirimir as principais dúvidas apresentadas por essa comunidade. Foram incluídas informações sobre os sinais e sintomas da doença em humanos e o que fazer em caso de suspeita da doença, bem como as formas de contaminação. Foram abordadas as práticas ambientais de prevenção dessa enfermidade, como segregação de resíduos sólidos e a importância de se evitar acúmulo de água e restos de alimentos em torno do domicílio.

Os exemplares do material de educação ambiental foram impressos pela gráfica da UFRGS (Figura 3) e a distribuição dos materiais se deu na Escola de Ensino Fundamental Porto Novo, em que estão matriculadas as crianças que moram nessa comunidade. Cerca de 250 crianças entre 5 a 12 anos receberam os materiais após a apresentação do projeto, realizada nas salas de aula, durante o período letivo, para cada turma individualmente. Nessa apresentação, as crianças reconheceram nas fotos as pessoas da comunidade e os animais (cães). Também foram explanadas as 


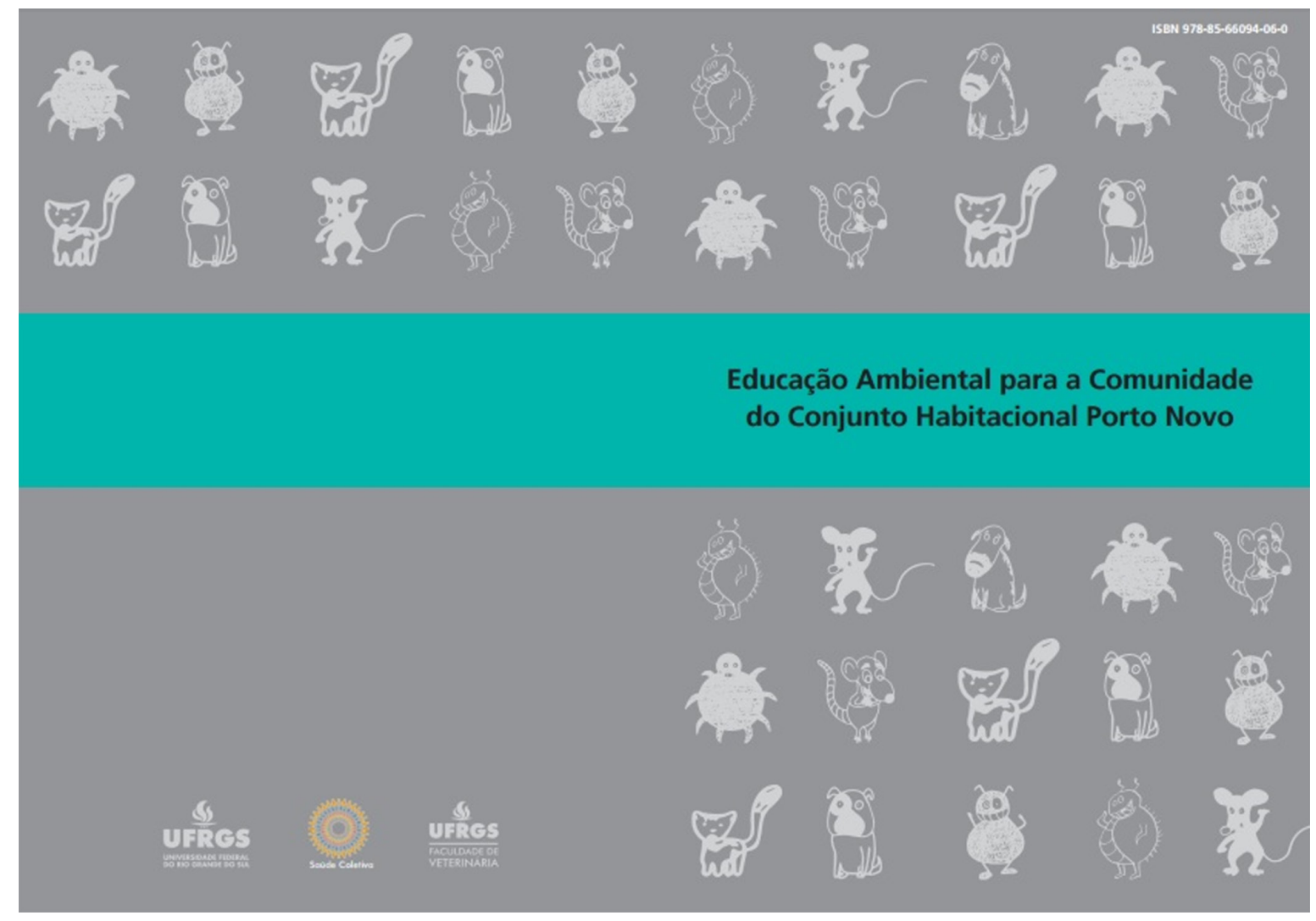

Figura 3. Capa do Material de Educação Ambiental para o Conjunto Habitacional Porto Novo, 2015. Fonte: Mesquita et al. ${ }^{17}$

medidas de prevenção da leptospirose e os cuidados ambientais necessários para se ter uma vida mais saudável.

\section{CONCLUSÃO}

O material de educação ambiental produzido foi uma sistematização dos dados coletados sobre a percepção de saúde dos moradores do novo reassentamento urbano Porto Novo com foco no ambiente e os resultados das sorologias anti-leptospira dos animais. Esse material foi idealizado para auxiliar na promoção da saúde e prevenção de doenças, em especial a leptospirose, por se tratar de uma doença muito comum em locais sem saneamento e com forte presença de ratos, como era o antigo local de moradia da comunidade. A leptospira está presente no ambiente e a leptospirose foi reconhecida por essa comunidade como a "doença do rato". Um número expressivo de entrevistados conhecia alguém que tinha tido leptospirose, e isso se deve ao fato de que essa comunidade provinha de uma área sem saneamento, onde eram relatados muitos casos da doença. A frequência de soropositividade nos cães não diferiu da de outros trabalhos publicados em várias partes do país, no entanto uma maior prevalência da sorovariedade Icterohaemorrhagiae observada indica o risco para a população, visto ser essa a que produz um quadro clínico mais severo nas pessoas.
Embora essa comunidade tenha sido reassentada em local com saneamento básico, equipamentos urbanos e galpão comunitário de reciclagem, antigos costumes ainda permanecem, como a prática de acumular materiais recicláveis em torno das residências, o que torna o ambiente propício à atração de ratos, trazendo riscos à saúde dos vizinhos e da própria família. A frequência de soropositividade para leptospira de 18\% indica que a bactéria está no ambiente e deve ser combatida com ações de educação ambiental e sensibilização da comunidade para os riscos a que estão sujeitos. Deve-se destacar a importância do trabalho de educação e conscientização ambiental como um instrumento concreto de prevenção de zoonoses, sendo essas ações parte da promoção e vigilância em saúde.

\section{AGRADECIMENTOS}

Os autores agradecem à Pró-Reitoria de Pesquisa e Pró-Reitoria de Extensão da Universidade Federal do Rio Grande do Sul, pelo auxílio financeiro e bolsas de iniciação científica para as alunas; à Jaqueline Costa de Jesus, assistente social, por transmitir seu conhecimento e experiência indispensáveis a execução do presente trabalho. 


\section{REFERÊNCIAS}

1. Instituto Trata Brasil. Pesquisa Instituto Trata Brasil na Comunidade: Vila Dique - Porto Alegre (RS) [Internet]. São Paulo; 2011 [citado em 2013 nov 12]. Disponível em: http://www.tratabrasil.org.br/vila-dique-porto-alegre-rs

2. Acha P, Szyfres B. Zoonosis y enfermidades transmisibles comunesal hombre y a lós animales. 2. ed. Washington: Organização Panamericana da Saúde; 1989.

3. Genovez ME. Leptospirose em cães. Pet Vet. 1996;1:6-9.

4. Troleis AL. Metrópole de risco: o caso da Vila Dique e do aterro sanitário da zona norte na poluição das águas superficiais e subterrâneas das bacias hidrográficas dos Arroios da Areia e Passo das Pedras/Porto Alegre-RS [tese]. Porto Alegre: Universidade Federal do Rio Grande do Sul; 2009.

5. Gil CZV. Da Vila Dique ao Porto Novo: extensão popular, rodas de memórias e remoções urbanas. São Leopoldo: Oikos; 2013.

6. Zacarias IR, Bavaresco CS. Conhecendo a realidade dos catadores de materiais recicláveis da Vila Dique: visões sobre os processos de saúde e doença. Revista Textos \& Contextos (Porto Alegre). 2009;8(2):293-305.

7. Lilenbaum W, Rodrigues F, Barboza F. Aglutininas antileptospiras em caninos do município de Oriximiná, Pará, Brasil. R Bras Ci Vet. 2000;7(3):133-5. http://dx.doi.org/10.4322/rbcv.2015.198.

8. Aguiar DM, Cavalcante GT, Marvulo MFV, Silva JCR, Pinter A, Vasconcellos $\mathrm{SA}$, et al. Fatores de risco associados à ocorrência de anticorpos antiLeptospira spp. em cães do município de Monte Negro, Rondônia, Amazônia Ocidental Brasileira. Arq Bras Med Vet Zootec. 2007;59(1):70-6. http:// dx.doi.org/10.1590/S0102-09352007000100012.

9. Silva WB, Simões LB, Lopes ALS, Padovani CR, Langoni H, Modolo JR. Avaliação de fatores de risco de cães sororreagentes à leptospira spp. e sua distribuição espacial, em área territorial urbana. Braz J Vet Res Anim Sci. 2006;43(6):783-92.

10. Brasil. Ministério da Saúde. Guia de vigilância em saúde. Brasília: Ministério da Saúde; 2014.
11. Jouglard SDD, Brod CS. Leptospirose em cães: prevalência e fatores de risco no meio rural do Município de Pelotas, RS. Arq Inst Biol (Sao Paulo). 2000;67(2):181-5

12. São Paulo. Secretaria Municipal de Saúde da cidade de São Paulo. Centro de Controle de Zoonoses. Animais sinantrópicos: manual do educador como prevenir [Internet]. São Paulo: Prefeitura de São Paulo; 2007 [citado em 2014 mar 23]. Disponível em: http://www.prefeitura.sp.gov.br/cidade/ secretarias/upload/Sinantropicos_1253903561.pdf.

13. Lermen HS, Fisher PD. Percepção ambiental como fator de saúde pública em área de vulnerabilidade social no Brasil. Revista de APS. 2010;13(1):6271.

14. Dias GF. Educação ambiental: princípios e práticas. 9. ed. São Paulo: Gaia; 2010

15. Santos LMP, Carneiro FF, Hoefel MGL, Santos W, Nogueira TQ. The precarious livelihood in waste dumps: a report on food insecurity and hunger among recyclable waste collectors. Rev Nutr. 2013;26(3):323-34. http://dx.doi.org/10.1590/S1415-52732013000300007.

16. Jorge S, Recuero RC, Recuero ALC, Oyarzbal MEB, Piltcher MG, Dias DG, et al. Prevalência de leptospirose em cães domiciliados sugere implantação de programa de educação em saúde. In: Anais do $14^{\circ}$ Congresso de Iniciação Científica da Universidade Federal de Pelotas; Pelotas, BR. Pelotas: Universidade Federal de Pelotas; 2005. 4 p. [citado em 2016 mar 14]. Disponível em: http://www2.ufpel.edu.br/cic/2005/arquivos/ conteudo_CB.html\#00731

17. Mesquita MM, Trevilato GC, Jantzen MM, Saraiva LH, Pretto MP, Garcia MIF, et al. Educação Ambiental para a comunidade do conjunto habitacional Porto Novo. Porto Alegre: Editora da Universidade Federal do Rio Grande do Sul; 2015. $31 \mathrm{p}$.

Recebido em: Jan. 05, 2016 Aprovado em: Mar. 03, 2016 